EXTENDED REPORT

\title{
Combined cataract and glaucoma surgery with mitomycin C: phacoemulsification-trabeculectomy compared to phacoemulsification-deep sclerectomy
}

\author{
C L Funnell, M Clowes, N Anand
}

Br J Ophthalmol 2005;89:694-698. doi: 10.1136/bjo.2004.055319

See end of article for authors' affiliations .......................

Correspondence to: Mr Nitin Anand, Department of Ophthalmology, Huddersfield Royal Infirmary, Lindley, Huddersfield HD3 3EA, UK; nitin.anand@ lycos.co.uk

Accepted for publication 11 October 2004
Aims: To compare outcomes of phacoemulsification combined with trabeculectomy (PT) or deep sclerectomy (PDS) with intraoperative mitomycin C (MMC) application.

Methods: Non-randomised, consecutive, retrospective comparative study. 97 eyes of 97 patients (59 PDS, $38 \mathrm{PT})$ undergoing combined surgery with intraoperative $M M C(0.1-0.4 \mathrm{mg} / \mathrm{ml}$ for 1-3 minutes) were identified for inclusion in the study.

Results: The probability of maintaining intraocular pressure (IOP) below $19 \mathrm{~mm} \mathrm{Hg}$ and $15 \mathrm{~mm} \mathrm{Hg}$, with a $30 \%$ drop from preoperative IOP and without additional medication, 1 year after surgery were $77.6 \%$ (95\% Cl: 67 to 90$)$ and $71.5 \%$ (60 to 85$)$ for the PDS group and $89.5 \%$ (80 to 99) and 89.5 (80 to 99) for the PT group, respectively, and these differences were not statistically significant ( $p>0.05, \log$ rank test). After excluding ocular co-morbidity no differences were observed in the improvement of visual acuity between the two groups. There were no major differences in the complication rates except that delayed bleb leaks were seen in seven eyes $(18.4 \%)$ of the PT group $(p=0.004)$.

Conclusion: In this study, no statistically significant difference was found in the IOP and visual outcomes between PDS and PT. A significantly higher frequency of late bleb leaks after PT was observed.
$\mathrm{T}$ he decision to do sequential or combined cataract and glaucoma surgery depends on several individual patient factors including the degree of visual impairment, target intraocular pressure (IOP), stage of glaucoma, compliance, age, and life expectancy. ${ }^{1-3}$

Combined phacoemulsification and trabeculectomy (PT) is the most widely reported procedure for combined surgery. ${ }^{4}$ Augmentation of the procedure with mitomycin C (MMC) has been shown to be beneficial when risk factors for failure are present. $^{2}$

Newer surgical techniques, loosely termed as non-penetrating glaucoma surgery (NPGS), have been reported to successfully lower IOP in the long term. ${ }^{56}$ Compared to trabeculectomy, the IOP lowering efficacy of NPGS is the same or less depending on the publication but all randomised trials agree that the complication rates are less with NPGS. ${ }^{7-11}$ The success rates of deep sclerectomy can be improved and IOPs in the low teens achieved using by intraoperative MMC application and postoperative Nd:YAG laser goniopuncture in selected cases. ${ }^{12}$

Reports suggest that phaco-deep sclerectomy (PDS) and phaco-viscocanalostomy (PVCT) are effective in lowering IOP. ${ }^{13-16}$ MMC augmentation of PDS has not previously been reported. The aim of this study was to compare the outcomes of PT with MMC and PDS with MMC and selective Nd:YAG laser goniopuncture.

\section{METHODS}

Consecutive patients undergoing combined glaucoma and phacoemulsification surgery with intraoperative MMC between September 2001 and November 2003, were identified from an ongoing correlational database (Microsoft Access) of all glaucoma surgery performed by the glaucoma unit. The surgeries were done or closely supervised by one surgeon (NA). The decision to do PDS or PT was based on several factors including available operating theatre time and training requirements for specialist registrars. In all cases a fornix based conjunctival flap was made. The MMC application technique was similar for both procedures and was done before dissection of the scleral flap. Two to four collagen sponges (Visitec, UK), soaked in MMC $0.1-0.4 \mathrm{mg} / \mathrm{ml}$ $(0.2 \mathrm{mg} / \mathrm{ml}$ in most cases), were applied into the subTenon's space for 1-4 minutes. PT was done by a same incision technique described elsewhere. ${ }^{17}$

PDS technique was standardised during this study. Firstly, a superior DS was done by a technique detailed in previous publications. ${ }^{12} 18$ This was followed by a temporal clear corneal phacoemulsification. In case of small, microscopic perforations, the procedure was completed as a DS. A peripheral iridectomy was performed in those with larger or posterior perforations and those with iris prolapse.

Postoperatively all patients received a topical steroid and antibiotic combination for 6 weeks or more depending on bleb appearance. If signs of bleb failure developed, subconjunctival betamethasone $(0.1 \mathrm{ml}, 0.4 \mathrm{mg})$ and 5 -fluorouracil (5-FU) $(0.2 \mathrm{ml}, 5 \mathrm{mg})$ were administered. In PT eyes, selective argon laser suture-lysis or removal of scleral sutures was performed. In PDS eyes, not achieving target IOP levels, Nd:YAG laser goniopuncture was done. This involved using the YAG laser in the free running Q-switched mode, energy ranging from 2-4 $\mathrm{mJ}$ and a Lasag 15 gonioscopy contact lens (CGAL, Haag-Streit). Three to 20 shots were applied. ${ }^{19}$

Analysis was done on intention to treat basis and eyes complicated by perforation during DS were included in the PDS group. Statistica 6 (Statsoft Inc, USA) was used for statistical analyses. IOPs below 19 and $15 \mathrm{~mm} \mathrm{Hg}$, with a 30\% reduction from preoperative IOP and without additional

Abbreviations: 5-FU, 5-fluorouracil; IOP, intraocular pressure; MMC, mitomycin C; NPGS, non-penetrating glaucoma surgery; PT, phacoemulsification combined with trabeculectomy; PDS, phacoemulsification combined with deep sclerectomy; PVCT, phacoemulsification combined with viscocanalostomy; TDM, trabeculoDescemet's membrane 
Table 1 Patient demographics and preoperative characteristics

\begin{tabular}{|c|c|c|c|}
\hline & $\begin{array}{l}\text { Phaco-deep } \\
\text { sclerectomy }\end{array}$ & $\begin{array}{l}\text { Phaco- } \\
\text { trabeculectomy }\end{array}$ & p Value \\
\hline Number of eyes & 59 & 38 & \\
\hline Age (years) (SD) & $78(8.5)$ & $78(8)$ & 0.55 \\
\hline Male/female & $34 / 25$ & $19 / 19$ & 0.59 \\
\hline \multicolumn{4}{|l|}{ Race } \\
\hline White & $54(91.5 \%)$ & 36 (94.7\%) & \\
\hline Afro-Caribbean & $3(5.1 \%)$ & $2(5.3 \%)$ & \\
\hline Indian & $2(3.4 \%)$ & & \\
\hline \multicolumn{4}{|l|}{ Diagnosis } \\
\hline POAG & $47(79.7 \%)$ & $27(71.1 \%)$ & 0.46 \\
\hline NTG & $5(8.5 \%)$ & $7(18.4 \%)$ & \\
\hline PXF & $6(10.1 \%)$ & $1(2.6 \%)$ & \\
\hline Steroid induced ACG & $1(1.7 \%)$ & $3(7.9 \%)$ & \\
\hline \multicolumn{4}{|l|}{ Co-existing ocular pathology } \\
\hline ARMD & 4 & 3 & \\
\hline Retinitis pigmentosa & 1 & 0 & \\
\hline Epiretinal membrane & 1 & 1 & \\
\hline High myopia & 3 & 0 & \\
\hline Diabetic retinopathy & 1 & 1 & \\
\hline Chronic anterior uveatis & 1 & 0 & \\
\hline Ocular surface disorder & 3 & 1 & \\
\hline Previous laser & & & 0.29 \\
\hline Peripheral iridotomy & $1(1.7 \%)$ & $3(7.9 \%)$ & \\
\hline Laser trabeculoplasty & $1(1.7 \%)$ & $1(2.6 \% 0$ & \\
\hline \multicolumn{4}{|l|}{ Previous surgery } \\
\hline Trabeculectomy & $3(5.1 \%)$ & $3(7.8 \%)$ & 0.89 \\
\hline RD surgery & $1(1.7 \%)$ & $1((2.6 \%)$ & \\
\hline \multicolumn{4}{|l|}{ Glaucoma medications } \\
\hline Median & 2 & 2 & 0.84 \\
\hline Range & $1-4$ & $0-4$ & \\
\hline \multicolumn{4}{|l|}{ IOP control before surgery } \\
\hline Uncontrolled IOP (mm Hg) & $31(81.6 \%)$ & $46(78 \%)$ & 0.86 \\
\hline Controlled IOP $(\mathrm{mm} \mathrm{Hg})$ & $7(18.4 \%)$ & $13(22 \%)$ & \\
\hline Mean follow up (months) (SD) & $16.0(9.0)$ & $19.4(7.6)$ & 0.054 \\
\hline Target IOP (mm Hg) (SD) & $14.8(1.8)$ & $13.6(1.2)$ & 0.001 \\
\hline
\end{tabular}

medication, were the two criteria of success used in the Kaplan-Meier survival analysis. Comparisons between the two groups were done by log rank test. Needle revision and laser goniopuncture were not considered to be failures. However, a subsequent operative procedure to lower IOP was considered as failure. Dichotomous variables were analysed using $\chi^{2}$ tests with Yates's correction and the Fisher's exact tests. Analyses of variance (ANOVA) were used for continuous variables. Non-parametric data were analysed by the

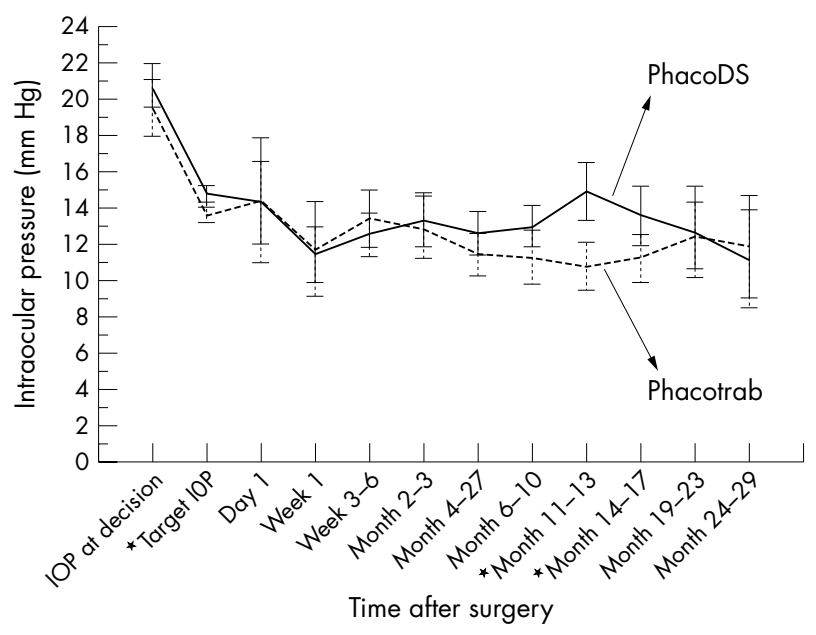

Figure 1 IOP changes after combined phacoemulsification combined with deep sclerectomy (PhacoDS) and phacoemulsification combined with trabeculectomy (Phacotrab). Error bars represent 95\% confidence intervals of means.
Mann-Whitney U tests. All tests were two tailed and $\mathrm{p}$ values less than 0.05 were taken to be significant.

\section{RESULTS}

A total of 97 eyes of 97 patients were eligible for the study. One patient was excluded, as she died 2 months after surgery. Six $(6.1 \%)$ patients died during the course and data were censored at the point of their demise. There were no significant differences in the preoperative characteristics of the two groups, except in the PT group the target IOPs, were significantly lower and follow up was longer (table 1 ).

IOP changes after surgery are shown in figure 1. IOP data was included till end of follow up even if patients were placed on glaucoma medications or had another procedure to lower IOP. Figures 2 and 3 show Kaplan-Meier survival curves for IOP below $19 \mathrm{~mm} \mathrm{Hg}$ and $15 \mathrm{~mm} \mathrm{Hg}$. The log rank test showed no differences in the survival analyses with both success criteria $(\mathrm{p}>0.05)$.

At last follow up, five eyes (13.2\%) of the PT group were on an average of 1.6 glaucoma medications and six eyes ( $10.1 \%$ ) of the PDS group were on an average of 1.16 medications to control IOP. This difference between groups was not significant $(p=0.76)$. After excluding ocular co-morbidity, no differences were observed in the improvement of visual acuity between the two groups $(p=0.48)$. Causes of a decrease of two Snellen chart lines from preoperative VA included age related macular degeneration (ARMD) (one eye, PT group), epiretinal membrane (one eye, PT group), ischaemic central retinal vein occlusion (one eye, PDS group).

Surgical complications are shown in table 2 and subsequent procedures in table 3. Eight out of 59 eyes in the PDS group $(13.5 \%)$ were complicated by intraoperative perforation of the trabeculo-Descemet's membrane (TDM) and the 


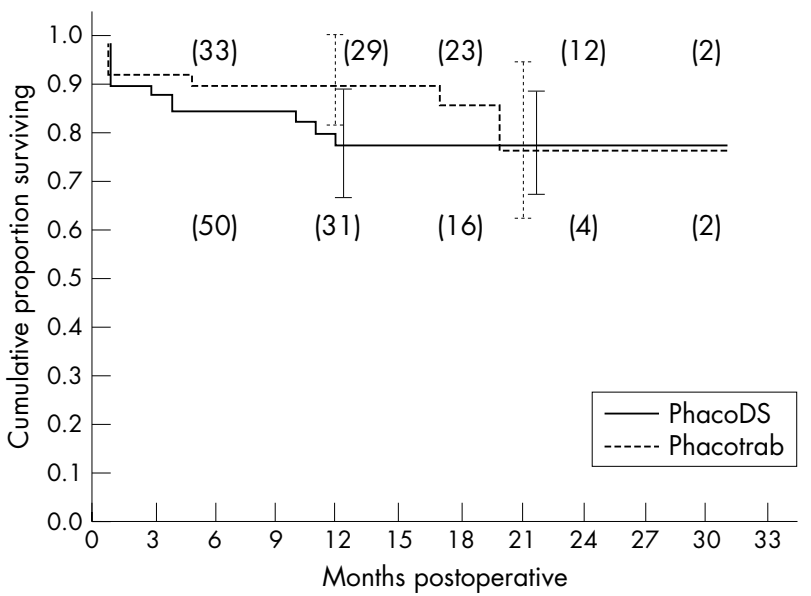

Figure 2 Comparing phacoemulsification combined with deep sclerectomy (PhacoDS) and phacoemulsification combined with trabeculectomy (Phacotrab) outcomes. Kaplan-Meier survival curves for maintaining IOP less than $19 \mathrm{~mm} \mathrm{Hg}$ without medication. Error bars represent 95\% confidence intervals. Numbers in parentheses represent number of eyes at risk at the specified time period. Log rank test, $p=0.5$.

complications of this subgroup are presented separately. There were no cases of bleb infection or endophthalmitis. The difference in frequency of late bleb leaks between the groups was highly significant $(\mathrm{p}=0.004)$.

\section{DISCUSSION}

Phaco-deep sclerectomy and phaco-trabeculectomy with MMC were found to have similar high success rates by the Kaplan-Meier survival analysis. Cox's proportional hazard model also showed no significant effect of the type of procedure (PT or PDS) on the success rates (table 4). However, in the 11-13 month and 14-17 month interval after surgery, IOPs were significantly lower in the PT group $(p<0.05$, ANOVA). The mean time for laser goniopuncture after PDS was 10.2 months. This explains the higher mean IOPs in the PDS group 1 year after surgery and the subsequent decline. More than half the eyes in the PDS group required laser goniopuncture for adequate IOP control. Outcomes compared well to the published literature despite more stringent definitions of success than generally reported. The National Trabeculectomy Survey reported outcomes of $64 \%$ of IOPs less than $16 \mathrm{~mm} \mathrm{Hg}$ at 1 year without medication. ${ }^{20}$ Gianoli et al found success rates of 59\% for PDS and $52 \%$ for PT at 1 year ${ }^{16}$ and Wishart et al $77 \%$ for DS and $94 \%$ for PDS at 3 years. ${ }^{15}$ Both, however, defined success as IOP of $21 \mathrm{~mm} \mathrm{Hg}$ or less without medication. This level of IOP

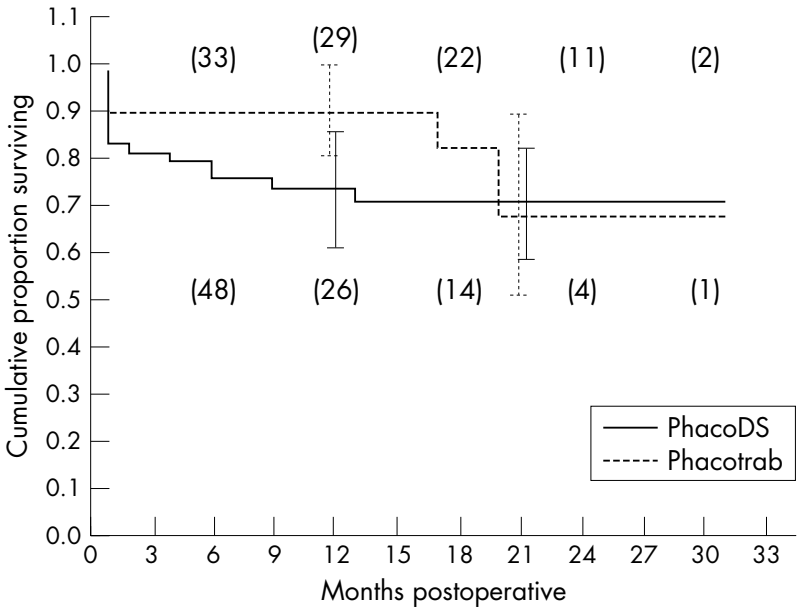

Figure 3 Comparing phacoemulsification combined with deep sclerectomy (PhacoDS) and phacoemulsification combined with trabeculectomy (Phacotrab) outcomes. Kaplan-Meier survival curves for maintaining IOP less than $15 \mathrm{~mm} \mathrm{Hg}$ without medication. Error bars represent $95 \%$ confidence intervals. Numbers in parentheses represent number of eyes at risk at the specified time period. Log rank test, $p=0.3$.

control may not be sufficient to control progression in eyes with advanced glaucoma. ${ }^{21}$

The above reports did not use MMC, which is reported to increase success rates for PT. Shin et al found MMC was beneficial in PT with a high risk of failure (African-American origin, IOP $>20 \mathrm{~mm} \mathrm{Hg}$ on maximum tolerated medication or at least two topical medications preoperatively). ${ }^{22}$ According to this definition the majority of the patients in this study would fall into this high risk category. Kozobolis et al randomised patients undergoing DS without an implant, to have or not have intraoperative MMC. IOP reduction was significantly greater in the DS-MMC group; however, rates of IOP of $21 \mathrm{~mm} \mathrm{Hg}$ or less at 3 years were only $42.5 \%$ of DS and $50 \%$ of DS-MMC. ${ }^{23}$ Laser goniopuncture was not performed in these patients and this may explain these indifferent results. Goniopuncture has been reported to significantly lower IOP months to years after surgery. ${ }^{19}$

MMC augmentation is associated with thin walled blebs and a high incidence of delayed bleb leaks and hypotony. ${ }^{24}$ In this study the rates of MMC related complications were low. There were no cases of bleb infections or endophthalmitis. Hypotony occurred in only two patients who underwent laser goniopuncture after PDS. The frequency of late bleb leaks was significantly higher $(18.4 \%)$ in eyes in the PT group than in the PDS group (0\%). One of the advantages reported by a previous study of PDS over PT was a lower incidence of

Table 2 Complications after combined surgery

\begin{tabular}{|c|c|c|c|c|}
\hline Complications & Phaco-trabeculectomy & $\begin{array}{l}\text { Phaco-deep } \\
\text { sclerectomy }\end{array}$ & $\begin{array}{l}\text { PDS-intraoperative } \\
\text { perforation }\end{array}$ & $\begin{array}{l}\text { p Value between } \\
\text { PDS all and PT }\end{array}$ \\
\hline No of eyes & 38 & 51 & 8 & \\
\hline Post-capsular rupture & $1(2.6 \%)$ & $3(5.9 \%)$ & 0 & 1.0 \\
\hline Transient shallow anterior chamber & $3(7.9 \%)$ & 0 & $2(25 \%)$ & 0.4 \\
\hline Hyphaema & $2(5.3 \%)$ & $3(5.9 \%)$ & $2(25 \%)$ & 0.7 \\
\hline Fibrin & $3(7.9 \%)$ & 0 & $1(12.5 \%)$ & 0.3 \\
\hline Transient conjunctival edge leak & $3(7.9 \%)$ & $3(7.7 \%)$ & $2(25 \%)$ & 1.0 \\
\hline Delayed bleb leaks & $7(18.4 \%)$ & 0 & 0 & 0.004 \\
\hline $\begin{array}{l}\text { Iris incarceration in sclerostomy/laser } \\
\text { puncture site/perforation of TDM }\end{array}$ & $1(2.6 \%)$ & $4(7.8 \%)$ & $2(25 \%)$ & 0.2 \\
\hline Delayed suprachoroidal haemorrhage & 0 & $2^{*}(3.9 \%)$ & $2(25 \%)$ & 0.1 \\
\hline Hypotony $(<5 \mathrm{~mm} \mathrm{Hg})$ & 0 & $2^{*}(3.9 \%)$ & 0 & 0.5 \\
\hline
\end{tabular}

TDM, trabeculo-Descemet's membrane.

${ }^{*}$ After $\mathrm{Nd}$ :YAG laser goniopuncture in one eye. 


\begin{tabular}{lll}
\hline $\begin{array}{l}\text { Table } 3 \text { Procedures after combined surgery } \\
\text { some eyes) }\end{array}$ & (more than one procedure was done on \\
\hline Procedure & Phaco-trabeculectomy & $\begin{array}{l}\text { Phaco-deep } \\
\text { sclerectomy }\end{array}$ \\
\hline $\begin{array}{l}\text { Laser suture-lyses/removal of releasable } \\
\text { scleral sutures }\end{array}$ & $18(47.4 \%)$ & $2(3.3 \%)^{*}$ \\
Nd:YAG laser goniopuncture & - & $30(51.7 \%) \dagger$ \\
Argon laser iridoplasty & - & $7(14.2 \%)$ \\
Needle revision & $10(26.3 \%)$ & $12(20.3 \%)$ \\
Total & $9(23.7 \%)$ & $8(13.5 \%)$ \\
With subconjunctival 5-FU & $1(2.6 \%)$ & $4(6.8 \%)$ \\
With subconjunctival MMC & $2(5.3 \%)$ & $3(5.2 \%)$ \\
Nd:ŸAG laser capsulotomy & $1(2.6 \%)$ & 0 \\
Conjunctival re-suturing & 0 & $2(3.3 \%)$ \\
Drainage of suprachoroidal haemorrhage & $1(2.6 \%)$ & 0 \\
Revision of trabeculectomy with intraoperative MMC & $2(5.3 \%)$ & 0 \\
Conjunctival advancement and bleb reduction for & $2(5.3 \%)$ & 0 \\
dysthaesia & $1(2.6 \%)$ & $1(1.7 \%)$ \\
Bleb repair and conjunctival autograft for delayed leak & $2(1.7 \%)$ \\
Deep sclerectomy with MMC & $1(2.6 \%)$ & 0 \\
IOL exchange & $1(2.6 \%)$ & \\
Ptosis repair & & \\
\hline *PDS eyes with intraoperative perforation. & & \\
tIncludes three eyes with intraoperative perforations. & &
\end{tabular}

Table 4 Results of Cox's regression models for the two success criteria

\begin{tabular}{|c|c|c|c|c|}
\hline & \multicolumn{2}{|l|}{ IOP $<19 \mathrm{~mm} \mathrm{Hg}$} & \multicolumn{2}{|l|}{ IOP $<15 \mathrm{~mm} \mathrm{Hg}$} \\
\hline & Hazard ratio $(95 \% \mathrm{Cl})$ & $p$ Value & Hazard ratio $(95 \% \mathrm{Cl})$ & $p$ Value \\
\hline Age at surgery (years) & 1.05 (0.99 to 1.08 & 0.06 & $1.03(0.67$ to 1.58 & 0.17 \\
\hline Sex & $8.42(2.18$ to 32.47$)$ & 0.0019 & 1.66 (0.70 to 3.93$)$ & 0.24 \\
\hline Surgery (PT or PDS) & $1.26(0.41$ to 3.90$)$ & 0.68 & 0.84 (0.34 to 2.64$)$ & 0.69 \\
\hline $\mathrm{IOP}<10$ at weeks $1-2$ & $0.60(0.19$ to 1.86$)$ & 0.36 & 0.91 (0.38 to 2.16$)$ & 0.82 \\
\hline IOP $<14$ at weeks $3-6$ & 0.60 (0.01 to 0.24$)$ & 0.00009 & 0.25 (0.10 to 0.62$)$ & 0.002 \\
\hline Transconjunctival oozing & 0.21 (0.04 to 1.04 ) & 0.055 & $0.18(0.05$ to 0.75$)$ & 0.02 \\
\hline
\end{tabular}

postoperative inflammation and other immediate complications like hyphaema and shallow anterior chamber. ${ }^{16}$ In this study, however, there was a low incidence of immediate side effects in both groups and the possible benefits of PDS were offset by a high incidence of intraoperative perforations (15.7\%).

IOP outcomes of PDS and PT with MMC augmentation were found to be similar in this study. This similarity in outcomes has previously been found between PDS and PT, but has not been reported using MMC. ${ }^{16}$ This study shows that both PDS and PT with MMC can be safe and effective procedures for achieving low IOPs in patients with glaucoma and cataract. The significance of these results are limited by study design - a non-randomised, retrospective comparative trial. There was also a possible bias against eyes undergoing PT as they had longer follow ups and probably more advanced glaucoma, as evidenced by the lower target IOPs. Finally, the surgeon's learning curve and technique must be taken into account. It is evident that most failures of the PDS group occurred within the first three postoperative months (figs 2 and 3). This may be related to problems with surgical technique. Shaarawy et al have shown in a prospective trial of DS that patients with an IOP $<6 \mathrm{~mm} \mathrm{Hg}$ on the first postoperative day had significantly fewer Nd:YAG goniopunctures and a longer median time to failure. ${ }^{25}$ The low first day IOP probably signifies adequate inner scleral flap dissection and juxtacanalicular trabecular meshwork removal. A prospective randomised controlled trial with procedures performed by experienced surgeons with long term follow up is required to assess whether PT or PDS with MMC is more successful.

\section{Authors' affiliations}

C L Funnell, West Yorkshire Rotation, Clarendon Wing, Leeds General Infirmary, Leeds, UK

M Clowes, N Anand, Department of Ophthalmology, Calderdale and Huddersfield NHS Trust, Huddersfield Royal Infirmary, Huddersfield HD3 3EA, UK

The authors have no financial interest in any of the products or devices mentioned in this paper.

\section{REFERENCES}

1 Shin DH, Ren J, Juzych MS, et al. Primary glaucoma triple procedure in patients with primary open-angle glaucoma: the effect of mitomycin $\mathrm{C}$ in patients with and without prognostic factors for filtration failure. Am J Ophthalmol 1998;125:346-52.

2 Shin DH, Kim YY, Sheth N, et al. The role of adjunctive mitomycin $C$ in secondary glaucoma triple procedure as compared to primary glaucoma triple procedure. Ophthalmology 1998;105:740-5.

3 Vass C, Menapace R. Surgical strategies in patients with combined cataract and glaucoma. Curr Opin Ophthalmol 2004;15:61-6.

4 Friedman DS, Jampel HD, Lubomski LH, et al. Surgical strategies for coexisting glaucoma and cataract: an evidence-based update. Ophthalmology 2002; 109:1902-13.

5 Shaarawy T, Nguyen C, Schnyder C, et al. Five year results of viscocanalostomy. Br J Ophthalmol 2003;87:441-5.

6 Shaarawy T, Karlen M, Schnyder C, et al. Five-year results of deep sclerectomy with collagen implant. J Cataract Refract Surg 2001;27:1770-8.

7 Ambresin A, Shaarawy T, Mermoud A. Deep sclerectomy with collagen implant in one eye compared with trabeculectomy in the other eye of the same patient. J Glaucoma 2002;11:214-20.

8 Carassa RG, Bettin P, Brancato R. Viscocanalostomy vs trabeculectomy. Ophthalmology 2002;109:410-1.

9 Jonescu-Cuypers C, Jacobi P, Konen W, et al. Primary viscocanalostomy versus trabeculectomy in white patients with open-angle glaucoma: a randomized clinical trial. Ophthalmology 2001;108:254-8.

10 Luke C, Dietlein TS, Jacobi PC, et al. A prospective randomized trial of viscocanalostomy versus trabeculectomy in open-angle glaucoma: a 1-year follow-up study. J Glaucoma 2002;11:294-9. 
11 El Sayyad F, Helal M, El Kholify H, et al. Nonpenetrating deep sclerectomy versus trabeculectomy in bilateral primary open-angle glaucoma. Ophthalmology 2000;107:1671-4.

12 Anand N, Atherley C. Deep sclerectomy augmented with mitomycin C. Eye (in press), 2005.

13 D'Eliseo D, Pastena B, Longanesi L, et al. Comparison of deep sclerectomy with implant and combined glaucoma surgery. Ophthalmologica 2003;217:208-11.

14 Uretmen O, Ates H, Guven S, et al. Comparison of outcomes of viscocanalostomy and phacoviscocanalostomy. Can J Ophthalmol 2003;38:580-6.

15 Wishart MS, Shergill T, Porooshani H. Viscocanalostomy and phacoviscocanalostomy: long-term results. J Cataract Refract Surg 2002;28:745-51.

16 Gianoli F, Schnyder CC, Bovey E, et al. Combined surgery for cataract and glaucoma: phacoemulsification and deep sclerectomy compared with phacoemulsification and trabeculectomy. J Cataract Refract Surg 1999;25:340-6.

17 Vass C, Menapace R. Surgical strategies in patients with combined cataract and glaucoma. Curr Opin Ophthalmol 2004;15:61-6.

18 Mermoud A, Schnyder CC. Nonpenetrating filtering surgery in glaucoma. Curr Opin Ophthalmol 2000;11:151-7.
19 Mermoud A, Karlen ME, Schnyder CC, et al. Nd:Yag goniopuncture after deep sclerectomy with collagen implant. Ophthalmic Surg Lasers 1999;30:120-5.

20 Edmunds B, Thompson JR, Salmon JF, et al. The National Survey of Trabeculectomy. III. Early and late complications. Eye 2002;16: 297-303.

21 The AGIS Investigators. The advanced glaucoma intervention study (AGIS): 7. The relationship between control of intraocular pressure and visual field deterioration. Am J Ophthalmol 2000;130:429-40.

22 Shin DH, Ren J, Juzych MS, et al. Primary glaucoma triple procedure in patients with primary open-angle glaucoma: the effect of mitomycin $C$ in patients with and without prognostic factors for filtration failure. Am J Ophthalmol 1998;125:346-52.

23 Kozobolis VP, Christodoulakis EV, Tzanakis N, et al. Primary deep sclerectomy versus primary deep sclerectomy with the use of mitomycin $C$ in primary open-angle glaucoma. J Glaucoma 2002;11:287-93.

24 Bindlish R, Condon GP, Schlosser JD, et al. Efficacy and safety of mitomycin-C in primary trabeculectomy: five-year follow-up. Ophthalmology 2002;109:1336-41.

25 Shaarawy T, Flammer J, Smits G, et al. Low first postoperative day intraocular pressure as a positive prognostic indicator in deep sclerectomy. Br J Ophthalmol 2004;88:658-61. 